\title{
Jornalismo de revista:
}

\section{um olhar complexo ${ }^{1}$}

Larissa Lauffer Reinhardt Azube/2

1 Trabalho apresentado no GP Jornalismo Impresso do XXXV Congresso Brasileiro de Ciências da Comunicação (INTERCOM), 2012.

2 Doutoranda em Comunicação Social pela PUC-RS, bolsista do CNPq, possui mestrado pela mesma instituição e graduação em Comunicação Social - Habilitação em Jornalismo pela Universidade Católica de Pelotas (2008). larissalauffer@gmail.com. 


\section{Resumo}

Neste estudo, buscamos compreender e explicar o jornalismo de revista em seus diversos aspectos complementares, concorrentes e antagônicos. Para isso, nos amparamos nos sete princípios do pensamento complexo, propostos por Edgar Morin: princípio sistêmico, princípio hologramático, princípio do anel retroativo, princípio do anel recursivo, princípio da auto-eco-organização, princípio dialógico e princípio da reintrodução. Deste modo, nos propomos a refletir sobre como o racional e o subjetivo, a ética e a estética, a natureza e a cultura, a sabedoria e a demência dialogam no meio de comunição em foco.

\section{Palavras-chave}

Jornalismo de revista, paradigma da complexidade, princípios do pensamento.

\section{Abstract}

In this study, we attempted to understand and explain the magazine journalism in its various aspects complementary, concurrent and antagonistic. For this, we rely on the seven principles of the complex thought proposed by Edgar Morin: systemic principle, hologramatic principle, principle of retroactive circuit, principle of recursive circuit, principle of self-eco-organization, dialogical principle and principle of reintroduction. Thus, we propose to reflect on how the rational and the subjective, ethics and aesthetics, nature and culture, wisdom and dementia dialogue in the focused medium.

\section{Keywords}

Magazine journalism, paradigm of complexity, principles of thought. 


\section{Um objeto relacional, relativo e múltiplo}

Significados diversos compõem o jornalismo de revista, enquanto objeto complexo. Funcionando em sintonia com seu tempo, magazines podem manter relação metonímica com a realidade, representando épocas e ajudando-nos ${ }^{3}$ a compreender a natureza, a história e a noosfera 4 de uma sociedade. "Ali estão os hábitos, as modas, os personagens de cada período, os assuntos que mobilizaram grupos de pessoas" (SCALZO, 2004, p. 16).

Revistas cobrem funções sociais que estão além e aquém do reportar. Podemos caracterizá-las por recrear, trazer análise, reflexão e experiência de leitura. Concomitantemente, são capazes de promover a miséria do pensamento, erigir mitos, sustentar estereótipos e fomentar ideologias. Assim, comportam, em relação de justaposição, tolerância e negociação, o conhecimento e a cegueira, a consciência e a incompreensão.

Por conseguinte, concebemos nosso objeto como um meio de comunicação, um negócio, uma marca, um produto; um conjunto de serviços: veículo sintetizador de informação, educação e entretenimento; uma história de amor com o leitor - com direito a rompimentos e reconciliações. É, também, "um fio invisível que une um grupo de pessoas e, nesse sentido, ajuda a construir uma identidade, ou seja, cria identificações, dá sensação de pertencer a um determinado grupo" (SCALZO, 2004, p. 12).

Revistas são veículos amplificadores, capazes de confirmar, explicar e aprofundar histórias já veiculadas por mídias mais imediatas. Em função da periodicidade, têm mais tempo para elaborar a pauta, checar e analisar informações, explorar diferentes ângulos, aprofundar o tema e ajustar o foco ao

3 No decorrer deste estudo, empregaremos a primeira pessoa do plural em conformidade com o método de pesquisa adotado, o "paradigma da complexidade", cujos pressupostos estabelecem a relação do "Eu" com o "Outro" na construção do conhecimento. Assim, este trabalho é o resultado da interação entre autora, cultura, lugar de produção, pensadores e futuro leitor.

4 Para Morin, a noosfera é uma atmosfera antropossocial, povoada por saberes, espíritos, imagens, ideias, mitos, lendas, deuses etc. O autor acredita que "essa esfera é como um meio, no sentido mediador do termo, interposto entre nós e o mundo exterior para fazer-nos comunicar com esse. É o meio condutor do conhecimento humano" (MORIN, 2011b, p. 140). 
leitor. Abordam assuntos e suas reportagens assumem caráter de recuperação dos acontecimentos para construção de textos interpretativos, atravessados, em variáveis graus, pela opinião.

A matéria de revista é geralmente uma reportagem descompromissada com o factual e com os acontecimentos rotineiros, objetivando muito mais uma interpretação dos fatos e a análise de suas consequências, pois raramente pode ou procura oferecer novidades no sentido do que é assegurado pelas emissoras de televisão, de rádio e pelos jornais (LUSTOSA, 1996, p. 104).

A objetividade faz parte das atribuições de uma reportagem pois, na medida em que esta busca precisão, confere verossimilhança entre relato e relatado. Ainda assim, para Sérgio Vilas Boas, o estilo de redação das revistas não combina com a imparcialidade mítica dos veículos informativos, pois todo texto, em especial o interpretativo, carrega consigo uma tendência. "A tendência de uma revista é a inclinação de seus leitores" (VILAS BOAS, 1996, p. 86).

Assim, objetividade e subjetividade, ciência e mito ${ }^{5}$, sabedoria e demência estão conjugadas, de maneira complementar, concorrente e antagônica, para compor o universo do objeto sobre o qual nos propomos a refletir a partir dos princípios do pensamento complexo. Apesar das marcas identitárias de cada revista, o jornalismo praticado nesse meio de comunicação apresenta características comuns. Esses aspectos gerais, inerentes à sua complexidade, são, por conseguinte, aqueles que nos interessam neste estudo. Isso porque acreditamos que através do todo podemos compreender as partes, sendo a recíproca também, em certa medida, verdadeira.

\section{A noção de complexidade: considerações sobre o método}

Enquanto método, a complexidade deriva do nosso percurso, comporta uma maneira própria de interligar o conhecimento, a qual pressupõe objetividade e subjetividade, descoberta e inovação. "O objetivo do método, aqui, é ajudar a

5 De acordo com Morin (2008, p. 203), "a ideia torna-se mito quando se concentra nela um formidável "animismo" que the dá vida e alma; ela se impregna de participações subjetivas quando aí projetamos nossas aspirações e, por identificação, a isso consagramos a vida". 
pensar por si mesmo, para responder ao desafio da complexidade dos problemas" (MORIN, 2008b, p. 36). Assim, nosso olhar deve contribuir para a reflexão sobre o jornalismo praticado nos magazines, de modo idiossincrático, com as marcas da reintrodução do sujeito, produtor do conhecimento.

Trazemos brevemente, neste momento, algumas noções sobre a epistemologia complexa. Começamos com a noção de paradigma proposta por Edgar Morin, a qual contém, para todas as falas que acontecem sob o seu campo, os conceitos essenciais ou as categorias-mestras de inteligibilidade e, concomitantemente, os tipos de relações coerentes de atração/repulsão (conjunção, disjunção, implicação ou outras) entre esses conceitos e categorias.

Semanticamente, o paradigma determina a inteligibilidade e dá sentido. Logicamente, determina as operações lógicas centrais. Ideo-logicamente, é o princípio primeiro de associação, eliminação, seleção, que determina as condições de organização das ideias. É em virtude desse triplo sentido gerativo e organizacional que o paradigma orienta, governa, controla a organização dos raciocínios individuais e dos sistemas de ideias que the obedecem (MORIN, 2011b, p. 261).

Quanto ao complexo, para Morin (2008b), trata-se do multidimensional inseparável, concomitantemente físico, biológico, cerebral, mental, psicológico, cultural, social. É dessa maneira que o autor concebe o homem: criador e criatura de um mundo igualmente complexo. "A complexidade é, efetivamente, o tecido de acontecimentos, ações, interações, retroações, determinações, acasos que constituem nosso mundo fenomenal" (MORIN, 1991, p. 18). No momento em que dialogamos com esse método para compreender o jornalismo de revista, nos propomos a mergulhar nessa trama multifatorial.

\section{Complexificando o olhar sobre as revistas}

A complexidade, portanto, guiar-nos-á, fornecendo as linhas mestras de um caminho que, ao trilhá-lo, construímos de um modo só nosso, conjugando razão e sensibilidade, de maneira indissolúvel. Propomo-nos, desta maneira, 
a compreender e explicar os aspectos complexos do jornalismo de revista, dentro de nossos limites pessoais, sociais e históricos, amparados nos sete princípios do pensamento complexo propostos por Morin: princípio sistêmico ou organizacional; princípio hologramático ou hologrâmico; princípio do anel retroativo; princípio do anel recursivo; princípio da auto-eco-organização; princípio dialógico; e princípio da reintrodução.

\section{A revista como sistema}

O princípio sistêmico ou organizacional liga o conhecimento das partes ao conhecimento do todo. É oposto ao reducionismo e defende que o todo é mais do que a soma das partes, posto que sua organização produz qualidades novas em relação a elas separadamente. Por outro lado, considera o todo, também, como menos do que a soma das partes, "cujas qualidades são inibidas pela organização do conjunto" (MORIN, 2000, p. 26). Assim, fragmentos e totalidade são indissociáveis.

Com base nesse princípio, as revistas nos parecem grandes sistemas de comunicação. O todo de um título carrega mais do que textos e fotografias impressos nas páginas, comportando uma visão de mundo, um imaginário acerca do leitor, um sistema ético próprio, normas e modos de operação singulares, uma concepção estética específica que pode determinar, por exemplo, a posição dos elementos gráficos e das informações.

Cada uma dessas partes imprime suas marcas no todo, que, na hibridização desses elementos, inibe algumas características e alcança outras, dentre as quais destacamos o simbolismo da revista para o leitor, as impressões que uma edição em particular pode causar e a simpatia ou antipatia que um título desperta nos grupos sociais, por exemplo.

Por conseguinte, por mais informações que as revistas utilizem para compor seus textos, estes nunca serão absolutos, nem contemplarão todos os aspectos da realidade. Entretanto, as partes deverão dar conta de retratar um 
todo, complexo e verossímil, aos leitores das publicações. Podemos considerar a parte como o relato que está ligado ao conhecimento do todo, ou seja, o acontecimento. O todo é mais e menos que a soma das partes.

Há ainda a questão organizacional do sistema, no que concerne ao fator humano da produção. Os trabalhos de cada jornalista, fotógrafo, publicitário, designer - isto é, de cada profissional envolvido na confecção de uma edição -, quando unidos na conjugação de esforços, apresentam características novas em relação às tarefas isoladas. O que era antes a soma de texto, foto, ilustração, revisão e processo de edição torna-se reportagem.

Ainda assim, os magazines não absorvem tudo daqueles que os fazem e daquilo de que são feitos. Seu significado para o leitor, em síntese, é menos do que todas as informações levantadas, entrevistas realizadas e linhas escritas. Fragmentos e totalidade são indissociáveis, em um processo de interação em que se revelam mutuamente.

Qualidades são inibidas na organização do conjunto, de forma que os objetos que estudamos são mais do que a soma dos esforços envolvidos na sua produção. Muitas revistas significam por si mesmas, independentemente do conteúdo desta ou daquela edição. Em outro modo de ver o todo, a publicação, em seu aspecto histórico, apresenta qualidades novas em relação às partes consideradas.

\section{A revista enquanto holograma}

Com o princípio hologramático ou hologrâmico, de Morin (2008b, p. 113), entendemos que a partir das partes podemos reproduzir o todo. "O holograma demonstra, pois, a realidade física de um tipo surpreendente de organização em que o todo está na parte que está no todo, e a parte poderia estar mais ou menos apta a regenerar o todo". Portanto, a organização complexa do todo pressupõe sua gravação nas partes singulares. 
Transpondo esse princípio para nosso objeto de pesquisa, podemos compreender que o jornalismo de revista, na contemporaneidade, faz parte de um todo que, por sua vez, compõe as histórias das revistas, as quais contêm e estão contidas em linhas editoriais, inseridas em contextos da produção de revistas em determinado país, com uma cultura social e profissional peculiares. Ao resgatar algumas edições passadas, podemos compreender melhor o que determinada revista representa hoje para seus leitores ou mesmo para aqueles que a rejeitam.

Podemos compreender o modus operandi de uma revista ao analisar algumas edições. Do mesmo modo, se temos uma noção generalista do significado de determinada revista, possuímos também elementos para desvendar seus porquês específicos, o que motiva cada edição ou mesmo cada texto ou foto. Somos capazes de ler não apenas o óbvio e o denotado, mas o obtuso, o conotativo e o não dito.

Ainda assim, ao observar algumas das revistas existentes, podemos compreender o funcionamento geral do gênero e apreender características comuns. A totalidade do patrimônio genético das revistas está em cada edição de cada título, da mesma maneira que o DNA humano é uno e múltiplo. E para explicar as modificações na feitura das revistas através dos tempos, podemos nos amparar nas palavras de Morin (2008b): "o todo dirige as atividades parciais que o dirigem".

Por conseguinte, cabe apontar aqui que o jornalismo de revista parece apresentar relação metonímica com a realidade. É parte dela, que é parte dele. Parte dela, que parte, em parte, dele. Estão tramados. A partir do que é relatado, podemos reconstituir o acontecimento, do mesmo modo que o jornalista reconstitui o fato por meio da escrita. Dessa maneira, o holograma dialoga com a ideia sistêmica, atestando que a correspondência entre eles nunca é exata. 


\section{Aspectos retroativos que se anelam nas revistas}

O terceiro princípio é o do anel retroativo: ele rompe com a ideia de causalidade linear, de forma que a causa age sobre o efeito e esse age sobre a causa. "O anel retroativo não é uma forma, mas permanece ligado a formas rotativas, isto é, comporta sempre circuitos ou ciclos" (MORIN, 2008a, p. 229). Queremos dizer que o que era causa pode se tornar consequência e vice-versa. Não existe uma regra universal que determine as posições ocupadas dentro dos processos de significação do homem e do mundo.

Fundado na Cibernética de Norbert Wiener, a qual "permite o conhecimento dos processos de autorregulação" (MORIN, 2000, p. 27), o conceito de retroalimentação aparece como uma propriedade que visa à autonomia e à estabilidade do sistema. Notamos, portanto, que as representações sociais das revistas interferem no modo como os leitores percebem os assuntos. Ciclicamente, essa percepção tende a legitimar o discurso das revistas. Assim, do mesmo modo como os magazines são capazes de influir na opinião dos leitores a respeito do real, as visões de mundo deles determinam pautas e abordagens, uma vez que este tipo de publicação, em geral, é voltado a públicos-alvo definidos.

Dessa maneira, o que era causa passa a ser efeito, que passa a ser causa, em um clico de retroações, as quais organizam o processo de confecção dos magazines. Assim define-se a entrada da pauta, o movimento das informações obtidas, a transformação em texto e a circulação do produto. E, antes mesmo de uma revista chegar às bancas, seu próximo número já está sendo pensado. Logo, o começo da edição seguinte pode iniciar antes do fim da anterior, já que há questões interdependentes, apesar da autonomia da edição que já está em circulação.

Para Morin (2000, p. 16), "o anel de retroação (ou feedback) possibilita, na sua forma negativa, reduzir o desvio e, assim, estabilizar um sistema", o que nos faz refletir sobre os mecanismos pelos quais as revistas se autorregulam: 
manuais de redação, códigos de ética e deontologia, normas internas da empresa jornalística, padrão de produção do material, adesão a ideias e conceitos (como as noções de objetividade e imparcialidade, por exemplo). Notamos, portanto, a prosaidade e a sabedoria inerentes aos processos.

Na forma positiva, ainda segundo o autor, o feedback é um mecanismo amplificador, o qual pode gerar ações e reações cada vez mais fortes. Essa questão nos remete, por exemplo, à concorrência entre títulos de um mesmo segmento, cada um disputando uma fatia do mercado editorial. A competição pode gerar narrativas cada vez mais espetaculares, imagens a cada edição mais chocantes, o que nos leva a informações a cada ciclo mais contestáveis sobretudo no caso do jornalismo de revista, em cujas páginas a interpretação encontra um habitat quase perfeito. Isso nos faz perceber a demência poética desses veículos de comunicação.

\section{O anel recursivo e os magazines}

A ideia seguinte, presente no princípio do anel recursivo, complementa a retroação. Segundo Morin (2008a, p. 232), "traz-Ihe uma dimensão lógica fundamental à organização ativa. Com efeito, a ideia de recorrência, em termos de praxis organizacional, significa logicamente produção-de-si e regeneração" (grifos do autor). Significa dizer que, isoladamente, nada pode gerar. Essa capacidade é inerente aos processos, na sua totalidade de referências e de influências, com a condição de se anelarem sobre si mesmos.

Entendemos, portanto, que os magazines não são capazes de gerar textos reais por si mesmos, pois só podem representar algo prévio. Assim, nossa cultura é gerada na (e pela) sociedade e reconstruída por eles. A sociedade traz os fatos à tona e os recebe novamente, trabalhados na linguagem, em um curso de re-produções ininterrupto.

Não sabemos onde começam ou terminam as construções da realidade; muitas vezes, os fatos são concebidos para as revistas (sejam fofocas sobre 
celebridades ou escândalos da administração pública) e aceitos como verdade em função da difusão das informações. Em outros casos, são construídos pelas revistas: capas, matérias e fotografias são produzidas e o "real" se "realiza" através das mentes e mãos dos editores. Constitui-se, assim, uma espécie de organização ativa do gênero, que produz os elementos e efeitos necessários à sua existência.

Dessa forma, os sentidos permanecem em movimento circular, se reabastecem ininterruptamente, seguindo o curso da vida que se refaz. O que era causa passa a ser efeito, que passa a ser causa, constituindo um circuito, cujo fim alimenta o começo, de maneira que a construção da realidade seja um processo constante na sociedade como no jornalismo de revista.

A ideia de recursão alimenta a noção de totalidade ativa. Isso quer dizer que nem sociedade nem revistas são isoladamente generativas, mas é na totalidade - e através de suas partes - que o processo se constitui, desde que se feche em si mesmo. Leitores e revistas estão em constante processo de (re)organização e (re)produção de si, em função um do outro e de si mesmos. A produção permanente, neste sentido, é uma regeneração constante de sociedade e revista, que ao mesmo tempo desejam e querem ser desejadas.

\section{Um objeto auto-eco-organizado}

Por sua vez, o princípio da auto-eco-organização traz as ideias de relativização da autonomia e da dependência. Morin esclarece que os seres vivos são auto-organizadores, que se autoproduzem incessantemente (a exemplo do que vimos no princípio anteriormente explorado).

Como têm necessidade de extrair energia, informação e organização no próprio ambiente, a autonomia deles é inseparável dessa autodependência, e torna-se imperativo concebê-los como auto-ecoorganizadores. O princípio de auto-eco-organização vale evidentemente de maneira específica para os humanos, que desenvolvem a sua autonomia na dependência da cultura, e para as sociedades que dependem do meio geo-ecológico (MORIN, 2000, p. 28). 
Pensamos que toda produção humana tem parte de humanidade; utilizando, portanto, a analogia, voltamos este princípio para nossa reflexão. O jornalismo de revista é um gênero consolidado, cuja expansão vai além da profusão de títulos nas bancas e chega à internet. Assim, acreditamos que as revistas têm papel relevante na esfera da comunicação de massa e se auto-produzem, por meio dos profissionais que nelas trabalham, com relativa autonomia.

Os modos de operação estão definidos e as rotinas estabelecidas; cada parte do todo, ou seja, cada profissional que compõe a unidade da revista sabe o que deve fazer para que o produto de seu trabalho constitua a unidade do magazine. É a interação entre as células desse corpo "revista" que o mantém em funcionamento, de modo que essa autonomia aparece como fenômeno organizacional nos magazines.

Na contemporaneidade, além disso, as revistas não precisam submeterse oficialmente a qualquer tipo de censura, tendo portanto autonomia para decidir sobre o que será notícia em suas páginas. Não obstante, devemos começar a relativizar esse aspecto "auto" e tratar dos fatores "eco(biossocial) lógicos" de nosso objeto.

Revistas existem para serem lidas, dependendo inevitavelmente de seu público - e algumas, inclusive, quase estritamente de seus assinantes. Elas estão organizadas de modo a captar as necessidades, os anseios, os desejos, os questionamentos dos leitores e transformá-Ios em pautas, assuntos que rendam matérias e que seduzam aqueles que folheiam suas páginas.

Na organização de uma revista, a dependência se evidencia, pois na confecção das reportagens diversos profissionais estão envolvidos e precisam um do outro para que o resultado seja satisfatório e mantenha a engrenagem em funcionamento. Outrossim, quando pensamos na concorrência, nos vemos diante de uma relação de autonomia e dependência de uma revista em relação à outra. Para permanecer vivo, quando a seleção cultural define sucessos e 
fracassos de tiragens, um magazine não depende apenas de si, mas também do que representa no segmento.

Pensamos que a revista depende (em maior ou menor grau) do funcionamento de cada uma de suas células, de seus leitores, de seus concorrentes, mas também de seus anunciantes. Globalmente, da economia para vender mais ou menos, da cultura de ler e da popularidade de seu segmento. Além disso, uma revista depende do que a sociedade produz que possa e mereça ser contado em suas páginas. Em suma, as revistas são dotadas de uma autonomia dependente em relação aos espíritos e às culturas que as alimentam.

\section{Diálogos possíveis}

O princípio dialógico abrange, para Morin (2008b), a associação de instâncias que, conjuntamente, são necessárias à existência, ao funcionamento e ao desenvolvimento de um fenômeno. Dessa forma, diversos saberes de diferentes áreas são permitidos (e necessários) para que entendamos determinado objeto, ser ou acontecimento. Há justaposição, tolerância e negociação entre conhecimentos, ao mesmo tempo complementares, concorrentes e antagônicos.

Na produção de textos para revistas, diversas fontes são consultadas. Para escrever uma matéria de economia, por exemplo, o jornalista conversa com especialistas, com donos de empreendimentos, com consumidores. Para falar de comportamento, podemos escutar psiquiatras, psicólogos, antropólogos, sociólogos, filósofos etc. Enfim, toda uma gama de vozes pode ser combinada dentro de uma mesma reportagem.

Se pensarmos que esses rumores se misturam na edição, veremos que são múltiplas as possibilidades de compreensão de um fenômeno. De maneira que o jornalista de revista - que em geral precisa aprofundar-se nos assuntos que reporta mais do que os profissionais de outra mídias - acaba 
utilizando diversas vozes sociais na tentativa de compreender e explicar os acontecimentos para os leitores. Na busca da completude, o jornalismo de revista consegue ser complexo.

Nas bancas é possível ver com clareza: diversos segmentos dialogam para compor o todo do jornalismo de revista, objeto complexo que se constitui de maneira complementar, concorrente e antagônica. Basta pensarmos na variedade de títulos e em como eles competem entre si pelo olhar do leitor; como eles se completam, no que concerne a corresponder aos diversos âmbitos possíveis de interesse dos sujeitos. Ao mesmo tempo, chocam-se por possuírem linhas editoriais diferentes, pela oposição entre discursos mais simbólicos/ mitológicos/mágicos e outros mais empíricos/técnicos/racionais.

Tanto na composição do texto, quanto na edição, ou mesmo em função do gênero, há um constante movimento político de forças que negociam espaços: subjetividade, objetividade; real, imaginário; estética, ética; material, espiritual; ciência, filosofia; sabedoria, demência etc. O diálogo entre magazine e leitor, no momento da leitura, é também um espaço por excelência de negociação de sentidos.

Mesmo o discurso pretensamente lógico está carregado de vapores fantasmáticos: cultura e experiências permeiam os espíritos/cérebros que fazem as revistas. Por conseguinte, os assuntos podem manter diálogos diacrônicos, estando em relação com uma edição; e/ou com a edição anterior; e/ou com aquela que ainda está por vir; e/ou com outras revistas da mesma editora; e/ ou com a concorrência.

As instâncias psicanalíticas também estão em constante processo de ordem-desordem-organização dentro do fazer revista. Na esfera biopulssional do ID, surgem as pautas, em uma lógica de atender aos desejos do publico - ou aos próprios desejos do jornalista ou, ainda, àquilo que ele pensa ou quer que o leitor deseje. Outrossim, colocam-se os insights e intuições presentes durante o processo de confecção da revista. 
O superego atua o tempo inteiro controlando os mecanismos de produção. Podemos aproximá-lo da figura do editor - esfera paterna da autoridade -, mas também das expectativas dos pares e do público em relação ao trabalho - figuras representativas do além-social. Na esfera individual do ego, está o desejo de satisfação, de prazer na realização dos produtos do ID, harmonizados com as exigências do superego.

De acordo com Morin (2008b, p. 110), perpassando todos os aspectos abordados aqui, há uma dialógica análise/síntese, que "comanda as operações perceptivas, desde os analisadores sensoriais até a constituição de uma representação sintética". Processos esses que constituem, portanto, o que representamos como jornalismo de revista. A relação entre tais instâncias permite-nos ver o objeto e sua "democracia".

\section{A reintrodução: relação entre sujeito e objeto}

Por fim, cabe versar sobre o princípio da reintrodução, o qual, como defende Morin, dá conta da participação do autor na construção do saber. "Somos co-produtores do objeto que conhecemos. Cooperamos com o mundo exterior e é esta co-produção que nos dá a objetividade do objeto [...] A objetividade diz igualmente respeito à subjetividade" (MORIN, 1991, p. 134).

Esse princípio pode ser aplicado tanto em nosso objeto de pesquisa, quanto em nossa análise propriamente dita. Entendemos, dessa forma, que, como sujeitos, temos papel fundamental na construção do conhecimento, pois é a partir de uma percepção e cognição específicas que temos determinados apontamentos. "Todo conhecimento é uma reconstrução/tradução por um espírito/cérebro numa certa cultura e num determinado tempo" (MORIN, 2000, p. 29).

Assim, o jornalismo de revista só é possível através da reintrodução do sujeito produtor do conhecimento. Desse modo, preceitos jornalísticos consagrados, como objetividade, imparcialidade e isenção, soam ultrapassados no caso veículo de características interpretativas aqui em foco. Eles apenas existem em coexistência, política, com seus opostos. 
As revistas, enquanto meios de comunicação, representam objetos e/ ou seres e/ou pessoas e/ou acontecimentos, oferecendo-nos algum tipo de conhecimento sobre eles. A reflexão do autor, a seguir, parece-nos muito adequadas para pensarmos a comunicação, de maneira que possamos aplicá-la ao jornalismo de revista:

A representação é cognoscente, cognoscível, analisável, descritiva por um espírito sujeito que, além do mais, pode, pela troca de informações e descrições com outros espíritos-sujeitos, objetivar melhor e enriquecer sua percepção e, nesse sentido, conferir o seu conhecimento do mundo exterior (MORIN, 2008b, p.132).

Na confecção do texto do magazine, por exemplo, o jornalista entra em contato com um acontecimento, que ele computa e sobre o qual cogita. Mas ele precisa de mais informações e de depoimentos que deem legitimidade ao relato. Então, entra em contato com as representações das fontes sobre o fato. O jornalista conhece os dados, enriquece sua percepção, realiza a análise e sintetiza, oferecendo a sua representação ao leitor - ainda que a "sua" história não seja apenas sua, tendo também influências de outros profissionais, como o editor.

Neste sentido, é válido enfatizarmos que a apreensão da realidade nunca é direta, mas se realiza através da mediação tradutora de sinais/signos/ símbolos. É por meio da linguagem que temos acesso a nós mesmos, ao outro, aos acontecimentos, ao jornalismo de revista. Portanto, é pela interpretação que chegamos ao conhecimento - e isso vale para o jornalista, em relação ao mundo dos acontecimentos, e para o leitor e para o analista, em relação aos magazines. Percebemos o conhecimento em sua multidimensionalidade; nele, objetividade e subjetividade se interpenetram em grandes ondas. 


\section{O olhar e a cegueira: evidências provisórias}

Ao procedermos com o fechamento de nossas cogitações, temos consciência de seu duplo: a abertura a reflexões futuras que possam dialogar com aquelas empreendidas neste momento. Estamos conscientes dos perigos da certeza de verdade nas ciências, em especial na Comunicação, e por isso acreditamos na importância da relativização do conhecimento que construímos. Ainda assim, acreditamos que, na síntese dialógica de nossa análise, pudemos lançar alguma luz relevante sobre a complexidade do jornalismo de revista.

A partir de observações a respeito do todo dos magazines, pudemos entender o funcionamento e os significados de suas partes. Percebemos qualidades inibidas e outras novas ao analisar o sistema de nosso objeto. Também pudemos compreender sua relação potencialmente metonímica com a realidade, por meio da trama hologramática.

Compreendemos a construção do real, em revista, através dos processos contínuos de retroação e recursão, em que causa e efeito se anelam numa espiral sem fim, capaz de se autorregular, autoproduzir e regenerar. Outrossim, percebemos essa autonomia interligada à ideia de dependência, inerente à autoeco-organização complexa.

Buscamos, por conseguinte, entender como as revistas dialogam em si, entre si, com o leitor e, até mesmo, com o analista. Percebemos, nesses diálogos, a marca democrática (em maior ou menor grau) da negociação de sentidos, ideias e valores. E isso nos leva a compreender a dimensão humana de nosso objeto: construto e construtor do homem e da sociedade contemporânea. 


\section{Referências}

LUSTOSA, E. O texto da notícia. Brasília: Universidade de Brasília, 1996.

MORIN, E. A cabeça bem-feita: repensar a reforma, reformar o pensamento. Rio de Janeiro: Bertrand Brasil, 2006.

. "Da necessidade de um pensamento complexo". In: SILVA, J. M.; MARTINS, F.

M. Para navegar no século XXI: tecnologias do imaginário e cibercultura. Porto Alegre: EDIPUCRS, 2000.

. Introdução ao pensamento complexo. Lisboa: Instituto Piaget, 1991.

. Meu caminho. Rio de Janeiro: Bertrand Brasil, 2010.

. O método I: a natureza da natureza. Porto Alegre: Sulina, 2008a.

. O método II: a vida da vida. Porto Alegre: Sulina, 2011a.

. O método III: o conhecimento do conhecimento. Porto Alegre: Sulina, 2008b.

. O método IV: as ideias: habitat, vida, costumes, organização. Porto Alegre:

Sulina, 2011b.

. O método V: a humanidade da humanidade. Porto Alegre: Sulina, 2007.

. O método VI: a ética. Porto Alegre: Sulina, 2011c.

SCALZO, M. Jornalismo de revista. São Paulo: Contexto, 2004.

VILAS BOAS, S. O estilo magazine: o texto em revista. São Paulo: Summus, 1996. 